\title{
TOMÁS MORO Y EL REVERSO OSCURO DE UTOPÍA: ALIENACIÓN Y CÁLCULO RACIONAL EN EL DISCURSO DISTÓPICO
}

\author{
Francisco J. Martínez Mesa \\ (Universidad Complutense de Madrid)
}

\section{RESUMEN}

Con la publicación de Utopía en 1516, se inauguró un nuevo género, el relato utópico moderno, caracterizado por la descripción de sociedades o comunidades imaginarias donde sus habitantes disfrutaban de una vida armónica y placentera. Sin embargo, a través de sus páginas, la obra también permite establecer espacios de continuidad con las modernas lecturas distópicas: muchos de sus pasajes también nos inscriben en un mundo de tribulación y sufrimiento donde no parece haber lugar para la esperanza. A partir de esa constatación, este artículo reflexiona sobre el papel central que el humanista Moro va a conceder a la ficción como instrumento de emancipación y acción crítica al servicio del hombre cara a dar respuesta a las difíciles condiciones planteadas en el curso de su existencia (cálculo racional de intereses, alienación) y que en la mayor parte de los casos tienen su origen en el curso de la misma acción humana.

PALABRAS CLAVE: Distopía, utopía, alienación, humanismo, crítica

\section{THOMAS MORE AND THE DARK BACK OF UTOPIA: ALIENATION AND RATIONAL CALCULATION IN DYSTOPIC DISCOURSE}

\begin{abstract}
With the publication of Utopia in 1516, a new genre was inaugurated: the modern utopian narrative characterized by the description of societies or imaginary communities where the inhabitants enjoyed a harmonious and pleasant life. However, through its pages, the work also allows us to establish spaces of continuity with modern dystopian readings: many of its passages also inscribe us into a world of tribulation and suffering where there seems to be no place for hope. Based on this observation, this article reflects on the central role that the humanist Moro will grant to fiction as an instrument of emancipation and critical action to the service of man in the face of his response to the difficult conditions raised in the course of his existence (rational calculation of interests, alienation) and that in most cases have their origin in the course of the same human action.
\end{abstract}


KEYWORDS: Dystopia, utopia, alienation, humanism, criticism

Con la publicación de Utopía por Tomás Moro en 1516, se inauguró un nuevo género, el relato utópico moderno, caracterizado por la descripción de sociedades o comunidades imaginarias en las cuales sus habitantes disfrutaban de una vida armónica y placentera. Sin embargo, aunque la mayor parte de aquellas obras remitían a escenarios idílicos y paradisiacos radicalmente diferentes de los vividos por autores y lectores, no todo se puede reducir a una mera colección de estampas gratificadoras. En sus páginas hay mucho de inquietud y desasosiego. Aunque más perceptible en su primera parte, resulta omnipresente en su conjunto: sobre sus protagonistas se cierne una conciencia de crisis, en torno a cuya resolución todos discuten y debaten sin aparente consenso. Existe un diálogo, pero lo antitético de las perspectivas imposibilita cualquier acercamiento. Bloqueadas todas las vías, la única alternativa posible parece ser la resignación.

Posiblemente, si el humanista inglés hubiera dado por concluida su obra al final de la primera parte, no hubiéramos acabado muy lejos de los escenarios descritos por muchos de los relatos distópicos que tanto auge han experimentado desde el siglo pasado hasta la actualidad: también en ellos se nos inscribe en un mundo de tribulación y sufrimiento, en un lugar sin esperanza. Sus sociedades se presentan como felices si quienes en ellas viven se muestran conformes y ajustan su existencia a las reglas establecidas, pero se tornan insoportables cuando se procede a la inversa y el foco se sitúa en la condición opresiva de esas normas y su impacto sobre la existencia humana.

Ahora bien, ¿existen vínculos de afinidad entre la obra de Moro y los relatos de corte distópico, stricto sensu? Desde luego, a nadie se le ocurre discutir la condición eutópica del texto... pero ¿contamos con los suficientes argumentos para defender una interpretación distópica de Utopía?

A nuestro juicio, un aspecto que puede arrojar alguna luz sobre el tema es el concepto de alienación que es posible extraer de Utopía y de todo el original entramado discusivo que lo sustenta. Creemos que tras la sombría descripción de Inglaterra que nos ofrece en sus páginas, hay un deliberado deseo del autor de reflexionar sobre el sentido real de los comportamientos humanos y el legítimo papel que le corresponde desempeñar al individuo a la hora de ver cumplidas sus aspiraciones. Analizar su relato y determinar su sentido, tal es el cometido de las páginas que siguen y que de ver confirmada nuestra hipótesis, probablemente nos permitan llegar a establecer un espacio de continuidad entre el dilema existencial sugerido por Tomás Moro a través de su fascinante juego de imágenes y el actual horizonte presentado por las modernas 
lecturas distópicas, donde las tan temibles líneas rojas parecen haber sido ya inevitablemente traspasadas.

\section{EL PAPEL DE LAS CREENCIAS}

En el Libro I de Utopía, Moro nos ofrece una visión ciertamente pesimista de la sociedad de su tiempo donde reina un clima de penuria, criminalidad y sinrazón generalizado del que no parece haber salida. Uno de los personajes centrales del relato, el avezado navegador y viajero Rafael Hytlodeo, es muy gráfico a la hora de resumir la situación: «Y ciertamente, cuando sólo uno vive en el lujo y los placeres mientras a su alrededor todo son lamentos y gemidos, es que cuida de una cárcel y no de un reino» ${ }^{1}$. A la vez que bastante escéptico con respecto a una solución cercana:

Así, pues, no hay ocasión de realizar ninguna acción benéfica, ya que es más probable que el mejor de los hombres sea corrompido por sus colegas que no se les corrija, ya que el perverso trato con éstos, o bien le deprava, o bien le obliga a disfrazar su integridad e inocencia con la maldad y la necedad ajenas ${ }^{2}$.

De su exposición se desprenden algunos rasgos que podrían invitarnos a pensar que nos encontramos ante una distopía, aunque con ciertas peculiaridades. La principal, sin duda, reside en la familiaridad que tal descripción genera en el lector: no necesita hacerle pensar desgracias y males imaginarios, porque los que aquí se le presentan son los reales y cotidianos. Es una distopía de carne y hueso, reconocible en nuestra vida y nuestros actos, a la que hoy más que nunca solemos recurrir cuando la realidad nos resulta inexplicable y la única alternativa que tenemos es concebirla como un escenario de pesadilla del cual no podemos escapar. Pero ese tipo de imágenes, ¿nos permiten hablar de una verdadera distopía?

Si nos guiamos por lo que nos dicen algunos especialistas en la materia, diríamos que no. En el caso de Lyman Tower Sargent en un conocido artículo, éste define a la distopia, (o utopía negativa) como «una sociedad inexistente descrita con detalle y localizada en un tiempo y un lugar que el autor pretende hacer ver al lector contemporáneo como considerablemente peor que la sociedad en la que éste vive» ${ }^{3}$. $\mathrm{Al}$ igual que Sargent, otros muchos autores (Moylan, Bouchard o Claeys, entre otros ${ }^{4}$ ) también insisten en la importancia del carácter idealizado o ficticio de los escenarios descritos en este tipo de obras, que desde luego no parece corresponderse con la mirada realista ofrecida por Moro de la Inglaterra de su tiempo. En efecto, lo que él

\footnotetext{
${ }^{1}$ Tomás Moro, Utopia (Madrid: Espasa Calpe, 2005), 78.

2 Moro, Utopía, 82.

${ }^{3}$ Lyman Tower Sargent, "The Three Faces of Utopianism Revisited,” Utopian Studies 5-1 (1994): 9.

4 Tom Moylan, Scraps of the Untainted Sky: Science Fiction, Utopia, Dystopia (Boulder: Westview, 2000), 9; Gregory Claeys, Dystopia: A Natural History (Oxford: Oxford University Press, 2016), 290. https://doi.org/10.1093/acprof:oso/9780198785682.001.0001 ; Guy Bouchard, L'Utopie Aujourd'Hui (Quebec: Gaetan Morin, 1985), 184-185.
} 
nos refiere en sus páginas remite al más inmediato aquí y ahora; nada que ver, por tanto, con las oscuras visiones del futuro lanzadas por las distopías y otros muchos autores, ya desde Hesíodo, a lo largo de la Historia.

Ciertamente, la aflicción y la inquietud que el humanista inglés nos traslada no están referidas en términos ideales sino absolutamente literales. En este sentido, su contenido es tan auténtico como lo podría ser ahora un reportaje periodístico o un documental.

La elección por el autor de un tono y un estilo literario muy concretos parece expresar una clara voluntad por parte de éste de trasladar a sus lectores al terreno de la ficción. El recurso a técnicas y juegos de imágenes y símbolos - los diálogos entre los protagonistas (Moro, Egidio e Hytlodeo) o con algunos representantes de la autoridad (por ejemplo, el cardenal Morton), las alusiones constantes a algunos autores clásicos (Séneca, Platón, etc.), o las referencias a las costumbres y leyes de los remotos pueblos visitados por Hytlodeo (acorianos, macarienses)- parece apuntar a un deseo de difuminar y rebajar el tono de severidad y crudeza con que se presentaba su realidad más inmediata. La metáfora deviene un instrumento de denuncia y crítica tan sutil que las imágenes que proporciona no pueden ser más potentes: «-Vuestras ovejas respondí-, que tan mansas suelen ser y que con tan poco se alimentan ahora, han empezado a mostrarse tan feroces y famélicas que hasta engullen hombres y devastan y despueblan campos, casas y ciudades» ${ }^{5}$.

A la vista de las crudas y descarnadas descripciones de las que hacen gala las distopías tradicionales en sus relatos -nada que ver con las ofrecidas por Moro en su obra Moro- es posible establecer la siguiente conclusión: mientras novelas como $U n$ mundo feliz o 1984 se nutren de la técnica literaria para dotar de verismo a sus escenarios imaginados, Utopía procede justamente a la inversa: se sirve del discurso narrativo y de sus herramientas para conferir ficción a la realidad.

Ahora bien, ¿por qué motivo el autor desea idealizar el presente? Nuestra hipótesis parte de la idea de que todo forma de una estrategia premeditada por parte de Moro para captar al lector del libro e introducirlo dentro de un juego, en el que probablemente rehusaría entrar si el escenario de partida fuera tan considerablemente incómodo.

Al obrar así, el humanista inglés desea evitar a sus contemporáneos una imagen tan descarnada de su existencia, consciente de que cualquier visión que muestre el mundo real en toda su miseria y sordidez, sin espacio alguno para la esperanza o la redención, difícilmente puede seducir o atraer; si algo acaba generando, en todo caso, es el desinterés cuando no el más absoluto rechazo en el lector.

\footnotetext{
${ }^{5}$ Moro, Utopía: 58.
} 
Y esto inevitablemente nos lleva al papel crucial desempeñado por las creencias. Para la mayoría de los contemporáneos, la vida constituía un continuo y prolongado rosario de sufrimientos donde la lucha por la subsistencia, cada vez más difícil y penosa, había llevado a muchos a caer en el crimen y la delincuencia. Pese a ello, reinaba una cierta confianza en las clases dirigentes y en las instituciones tradicionales a la hora de resolver la situación. ¿Cabría hablar de una actitud acomodaticia y conservadora en la población ante el cúmulo y gravedad de los problemas? Probablemente, pero erraríamos en el diagnóstico si no tuviéramos en cuenta la importancia de las creencias en la configuración de las identidades individuales y sociales así como el profundo impacto psicológico y emocional provocado en las personas en el caso de su fractura.

¿Pero por qué eran y siguen siendo tan importantes para los hombres las creencias? Básicamente porque son modelos del mundo, representaciones mentales de nuestro paisaje físico, social, emocional, espiritual y político ${ }^{6}$. Y son reglas para la acción -como señalaba el filósofo norteamericano William James ${ }^{7}$, porque nos ayudan a actuar en todo momento aunque, por supuesto, también acarreen consecuencias. Las creencias, en fin, moldean nuestra identidad y por consiguiente nuestras relaciones con todo cuanto nos rodea. En otras palabras, queremos estar en lo cierto sobre el mundo porque de ello depende sentirnos más seguros.

Por esa razón, cuando nos equivocamos -o percibimos que nos hemos equivocado-, al constatar nuestras creencias como erróneas, nos sentimos muy afectados. El hecho de ver nuestro modelo de acción quebrado, y, por tanto, enfrentarnos a nuestro error, suele acarrear generalmente un fuerte daño emocional que hiere nuestra percepción del yo con extremada facilidad.

Tomás Moro y sus amigos Pedro Egidio y Rafael Hytlodeo no compartían el optimismo de sus interlocutores o del resto de la población con respecto a la resolución de aquellos graves problemas, pero tenían muy claro cómo sería acogida su opinión sobre la realidad inglesa de su tiempo si esta se mostraba de manera franca y directa: inmediatamente hubiera sido rechazada e ignorada.

Ante el difícil dilema que se planteaba -rebatir las creencias dominantes sin la más mínima posibilidad de éxito, o bien callar, pese a lo insostenible e injusto de la situación- el futuro lord canciller, arbitraría una brillante solución completamente al margen de los esquemas políticos tradicionales y que tenía su punto de origen en el terreno de lo imaginario y la ilusión. Como recientemente nos ha mostrado K. Schulz, la principal virtud de la ilusión reside en su capacidad para apartarnos de la realidad, incurrir en el error, sin tener conciencia de habernos equivocado. O dicho más claramente: adentrarnos en el mundo de lo que no es real y de lo que no podemos hacer en la vida real, sin correr ningún riesgo. Sabemos que en la vida cotidiana los errores nos esperan aunque no estamos seguros de que nos gusten cuando lleguen. En

\footnotetext{
${ }^{6}$ Kathryn Schulz, En defensa del error (Madrid: Siruela, 2015) 93.

${ }^{7}$ William James, La voluntad de creer (Madrid: Encuentro, 2004): 15.
} 
el mundo de lo imaginario también sabemos que podemos y vamos a equivocarnos pero nuestra participación en él siempre es consentida. ¿Motivos? Probablemente porque cuando nos aproximamos a la realidad bajo el velo de la ficción podemos aventurarnos en el terreno de lo incierto y lo problemático sin necesidad de poner en entredicho nuestras creencias de partida y por tanto, sin temor a incurrir en el error ${ }^{8}$.

$\mathrm{Al}$ servirse de la ficción en su discurso narrativo, Tomás Moro buscaba eludir el previsible rechazo que iba a caer sobre sus propuestas. Pero, ¿sus parámetros estilísticos se asemejaban a los posteriormente manejados por la literatura distópica contemporánea?

A decir verdad, las concomitancias entre el divertimento propuesto en esta obra y el concepto de extrañamiento cognitivo ya ensayado por los formalistas rusos (Victor Shklovsky), el dramaturgo y poeta alemán Bertolt Brecht, y la mayoría de cultivadores de la distopía actual ${ }^{9}$, son a todas luces evidentes. La desfamiliarización también persigue trasladar al lector al terreno de lo imaginario y distanciarlo de su realidad más inmediata, sin que la sensación de esa nueva experiencia se traduzca en un peligro para el conjunto de sus creencias.

Ambas técnicas permiten al lector mostrarse más receptivo hacia la consideración de nuevas perspectivas sin sentirse obligado a cuestionar las propias. Asimismo propician cambios imperceptibles y graduales en la manera de interpretar la realidad por parte de los individuos, hasta el punto de llegar a llevarles a asumir algunas de las debilidades de su marco de creencias inicial. Ahora bien, toda la iniciativa queda en manos del lector, constituido como máximo intérprete de cuánto hay de él en el relato y absoluto protagonista a la hora de irse apropiando de los nuevos conocimientos y reemplazar aquellos que habían sido su referencia en el pasado. Quien lee, en suma, siente que el proceso de revelación que está experimentando es personal y propio, nunca inducido.

Sin embargo, a medida que transcurre el relato, van a ir surgiendo cuestiones, como por ejemplo, el dilema en torno al papel de los sabios y consejeros y a su responsabilidad en la resolución de los males del país (páginas centrales del Libro I), donde el autor parece requerir del lector una actitud más beligerante. Ya no se trata de asumir una serie de aspectos en pequeñas dosis sino de tomar mayor partido y, por tanto, afrontar cambios más bruscos en sus creencias. Cree Moro que el lector ya es más maduro y no va a reaccionar tan defensivamente. La libertad que se le ha ido concediendo desde el principio de la lectura, y que le ha permitido flirtear con las nuevas creencias, ha contribuido a reafirmar la identidad del lector y acrecentar su confianza en descubrir la verdad por sí mismo. Pero el proceso de sustitución de unas creencias por otras sólo llegará a su término cuando se haya alcanzado un punto de no retorno donde la antigua creencia ya solo será eso: antigua. Las revelaciones que han

${ }^{8}$ Schulz, En defensa, 70.

${ }^{9}$ Darko Suvin, Metamorphoses of Science Fiction: On the Poetics and History of a Literary Genre (Berna: Peter Lang, 2016), 15. 
llevado a los lectores a darse cuenta de lo erróneo de sus análisis son las mismas que también les invitan simultáneamente al hallazgo de una nueva verdad: surge entonces la toma de conciencia.

Porque ¿qué es la toma de conciencia sino una readecuación de las creencias nunca absolutamente instantánea ni radical- que nos lleva a asumir nuevas perspectivas y planteamientos y a considerar modelos de intervención en la realidad nunca antes contemplados?

Rafael Hytlodeo jamás hubiera podido formular su vigorosa crítica contra la sociedad e instituciones de su tiempo sin haber conocido previamente la nueva realidad representada por Utopía y otros reinos, que le habían abierto los ojos sobre la iniquidad e injusticia de sus contemporáneos ingleses:

Así reputo sinceramente por prudentísimas y santísimas las instituciones de los utópicos a quienes tan pocas leyes bastan para asegurar tan excelente gobierno que a la vez el mérito es recompensado y la distribución por igual permite que todos gocen de la abundancia de todas las cosas. Comparo estas costumbres y la de tantos países, donde siempre se están dictando leyes para que estén bien administrados y a pesar de ello nunca lo están bastante, en donde cada uno llama suyo a lo que posee y todas las leyes sobredichas no bastan para adquirir ni para asegurar los bienes, ni para distinguirlos de los otros, que también alegan su derecho de propiedad privada ${ }^{10}$.

La literatura utópica y distópica nos ha ofrecido innumerables muestras de esa toma de conciencia que lleva a los protagonistas de sus relatos a contemplar su realidad presente bajo una nueva luz. Por ejemplo, en El año 2000, la novela del escritor norteamericano Edward Bellamy, Julian West es un joven de origen acomodado, que viaja al Boston del año 2000 y contempla los extraordinarios avances y transformaciones experimentados en el futuro. Sin embargo, tras la vuelta de su viaje ya nada es igual: ni siquiera los extremos niveles de injusticia y desigualdad de su tiempo que, hasta ese momento, resultaban absolutamente naturales:

Nada de todo aquello era nuevo para mí. Con frecuencia había recorrido aquella parte de la ciudad, con frecuencia había experimentado repugnancia, mezclada con cierto asombro filosófico, al pensar en la miseria que pueden soportar los hombres sin dejar de aferrarse a la vida. Pero las abominaciones morales de mi siglo aparecían hoy bajo un nuevo aspecto, lo mismo que sus locuras económicas, y ante la visión de otro siglo había caído de mis ojos una venda. No consideraba ya, con una curiosidad endurecida, los tristes habitantes de aquel infierno como criaturas apenas humanas. Reconocía en ellos a mis hermanos, mis hermanas, mis padres, mis hijos, carne de mi carne y sangre de mi sangre. El hormigueo de la miseria humana que me rodeaba ya no ofuscaba únicamente mis sentidos, sino que entraba en mi corazón

\footnotetext{
${ }^{10}$ Moro, Utopía, 83.
} 
como la hoja de un cuchillo, de suerte que no pude reprimir suspiros y gemidos ${ }^{11}$.

Efectivamente, tanto Hytlodeo como West han accedido a una realidad desconocida, y lo han hecho por sí mismos, es decir, han logrado cuestionar sus antiguas creencias sin sentir cuestionada su identidad. Y todo a partir de un proceso de apropiación positiva que ha llevado a ambos a reorientar su sentido crítico contra sus anteriores creencias y no sobre ellos ${ }^{12}$. La toma de conciencia invita a la germinación de nuevas creencias y al desarrollo de patrones de comportamiento inéditos y hasta entonces inconcebibles tanto sobre el presente como sobre el futuro, que indiscutiblemente también acabarán incidiendo en el aquí y ahora.

Tomas Moro, en fin, desea llevar a sus lectores al nivel de percepción de Hytlodeo. Pero, si en el caso de éste, fueron sus exploraciones por tierras exóticas las que influyeron en su cambio, en aquellos, el itinerario de iniciación que se apunta es más original e imaginativo. Sólo a partir de él, cree Moro que los hombres pueden llegar a tomar conciencia de lo ficticio de sus creencias y del contrasentido de una existencia de cuyas disfunciones nadie parece haberse percatado.

\section{ESCENARIO SOCIAL Y CÁLCULO RACIONAL DE INTERESES}

Sin embargo, por aquel entonces, la situación social y económica de la Inglaterra de los Tudor ya era objeto de un intenso debate y discusión entre predicadores y humanistas (Latimer, Crawley, John Hales, sir Thomas Smith) ${ }^{13}$. El siglo XVI había asistido a una serie trascendentales cambios sociales y económicos asociados al capitalismo cuyo impacto se hizo sentir muy especialmente en la agricultura y la industria, sobre todo en lo referido a la cuestión de la tenencia de las tierras y al desarrollo del régimen de propiedad privada. En efecto, las desamortizaciones monásticas emprendidas por Enrique VIII y la práctica creciente de expropiación de tierras de campesinos y comunidades constituyeron el inicio de una etapa -de acumulación originaria de capital-, dominada por un nuevo mapa de relaciones en donde la condición privativa de bienes y medios de sustento indujo a un régimen de máxima competencia entre los hombres ${ }^{14}$.

Para el humanista inglés, el nuevo mundo que se venía gestando conducía a una sociedad donde los individuos, al adaptar su existencia a un cálculo racional de

${ }^{11}$ Edward Bellamy, El año 2000 (Madrid: Capitán Swing, 2011), 261.

12 Daniel Gilbert, Tropezando con la felicidad (Barcelona: Destino, 2006), 181.

13 Quentin Skinner, Los Fundamentos del pensamiento político moderno (México: Fondo de Cultura Económica, 1985), 241.

${ }^{14}$ Joyce Youings, Sixteenth-Century England (Londres: Penguin, 1984). Una visión panorámica más de la evolución social de Inglaterra a partir del siglo XVI: James Casey, "Historiografía inglesa: tendencias recientes en el estudio de la época moderna”, Chronica Nova 28 (2001), 105-127. 
intereses tan salvaje e inhumano, comenzaban a percibir a su prójimo como un obstáculo a su felicidad y, en consecuencia, como un enemigo a batir.

Y ello había que achacárselo, según el autor, a la incapacidad de las autoridades para detectar las señales y actuar más allá de sus propios intereses ${ }^{15}$, terminando por arrastrar al reino a un profundo clima de enfrentamiento y crisis donde en lugar de bienestar y riqueza solo había infelicidad y sufrimiento.

¿Pero por qué el nuevo marco normativo había llevado a los hombres a ser tan desdichados? En un principio, según Moro, el régimen de propiedad privada había surgido como un eficaz instrumento al servicio de los individuos mediante el cual podían disponer y gestionar sus bienes y recursos libre y personalmente, obteniendo a cambio el máximo provecho de los $\operatorname{mismos}^{16}$. Ahora bien, el carácter privativo y excluyente de su titularidad, o lo que es lo mismo, el hecho de que la propiedad se hallara sometida a la voluntad exclusiva de su único titular, resultaba del todo incompatible con la extensión de la condición de propietarios a todos los miembros de la sociedad. Un bien o un recurso dado podían pertenecer a una persona, pero a nadie más que a esa persona.

Si la felicidad se hacía descansar sobre la propiedad, el objetivo de todo hombre sometido a un entorno de recursos limitado pasaba inevitablemente por competir con sus semejantes, y recurrir para conquistarla a cuantos medios tuvieran a su alcance. No dejaba de ser además una contienda desigual porque quienes dispusieran de mayores recursos (bienes, relaciones, poder) gozaban siempre de una mejor situación para incrementar sus posesiones, al contrario que los más pobres, condenados a penar a perpetuidad en la más absoluta miseria:

Desde que cualquiera puede apoyarse en títulos positivos para adueñarse de todas las riquezas que pueda, un corto número de personas se las reparten por abundantes que sean, y a los demás sólo les dejan la pobreza, y sucede frecuentemente que los pobres sean más dignos de la fortuna que los ricos, ya que éstos son rapaces, inmorales e inútiles y, en cambio, aquéllos son modestos y sencillos y con su trabajo cotidiano son más provechosos para el Estado que para ellos ${ }^{17}$.

Pese a lo radical de los cambios operados, la mayor parte de la población no parecía ser consciente de la situación ni de sus graves consecuencias. Y, sin embargo, sus efectos ya eran patentes en todas las esferas de aquella sociedad: en su obsesión por alcanzar la dicha, los hombres habían extendido su competencia por la posesión a otros tipos de bienes inmateriales (personas, afectos e influencias). Pero pronto, el

${ }^{15}$ Nate Silver, La señal y el ruido (Barcelona: Península, 2014), 504.

${ }^{16}$ James Collin Davis, "L’Utopie et le Nouveau Monde 1500-1700”, en Utopia. La quête de la société idéale en Occident, dirs. Lyman Tower Sargent y Roland Schaer (París: Bibliothéque Nationale de France - Fayard, 2000):113.

${ }^{17}$ Moro, Utopia, 83. 
ansia por el éxito llevó a muchos a considerar que lo esencial, lo verdaderamente gratificante ya no eran los trofeos en disputa (bienes, riqueza, amor) sino el hecho mismo de someter y sentirse por encima de los demás, hasta el extremo de aceptar la derrota siempre que también perdiera el rival. Para Moro, la sociedad había engendrado un monstruo que, lejos de aparejar la felicidad de los hombres, les había conducido al infortunio:

(...) esta bestia feroz, soberana y madre de todas las plagas, que es la soberbia, la cual no mide su prosperidad por el bienestar personal, sino por la desgracia ajena.

Esta no podría convertirse en diosa si no quedaran miserables a quien poder dominar e insultar, cuya miseria realzara su felicidad, y si la exhibición de su opulencia no oprimiera y encolerizase a la pobreza de aquéllos. Esta serpiente infernal, al arrastrarse por los pechos de los mortales, les retrae y frena como una rémora de encontrar el camino hacia una vida mejor. Además está tan hincada en el corazón humano que es difícil arrancarla de allí18.

Es en este punto donde el autor de Utopía constata la condición alienada de sus conciudadanos. La propiedad y las instituciones sociales inicialmente forjadas por los hombres para la dicha humana habían acabado por someter a sus creadores: el hombre ya no era el protagonista de sus actos, había dimitido de su papel central en la existencia, para convertirse - en palabras de Henry David Thoreau- en «herramienta de sus propias herramientas ${ }^{19}$.

Para Moro, liberar al hombre de su actual alienación requería previamente reivindicar la condición sagrada e inviolable del individuo -Hytlodeo es claro: «no creo que todos los bienes de este mundo se puedan comparar con una existencia humana» ${ }^{20}$. $\mathrm{Y}$ aquí no distingue entre grupos y clases sociales diferentes porque para él ese sufrimiento es compartido: ni siquiera los ricos se encuentran a salvo. Sólo entonces, a partir del reconocimiento de este mal compartido y de la urgencia de un cambio radical en el escenario social presente, se podría retomar un camino común en el que, sin embargo, cada uno sería libre de obrar de acuerdo a su particular cálculo racional de intereses:

No tengo ninguna duda alguna de que, bien por interés de cada uno, o por obediencia a la autoridad de Cristo salvador, que en su infinita sabiduría no pudo ignorar qué era lo mejor, y en su bondad indicó lo que no era mejor, todo el mundo habría aceptado fácilmente las leyes de aquella república (Utopía) ${ }^{21}$.

\footnotetext{
${ }^{18}$ Ibídem, 171-172.

${ }^{19}$ Henry David. Thoreau, $W$ alden (Nueva York: Peter Pauper Press, 1994), 34.

${ }^{20}$ Moro, Utopía: 62

${ }^{21}$ Ibidem, 171.
} 
Frente a la alienación, Moro recurre a un eficaz antídoto: la imaginación, desde la cual el individuo es sometido a un proceso de extrañamiento que le lleva a cuestionar la consistencia de las creencias establecidas. La toma de conciencia libremente así adquirida ofrece al lector una nueva mirada, indiscutiblemente crítica, con respecto a aquella realidad a la que el hombre parecía haber hipotecado su destino.

Más tarde, y también desde la sugestiva senda abierta por la ficción, Moro nos describirá en el Libro II un escenario social alternativo, la isla de Utopía, que -como él mismo insiste- no deja de ser absolutamente aleatorio y circunstancial -es así pero bien podría haber sido de otra manera. Y lo es porque su interés no reside tanto en mostrarnos una sociedad antitética a la inglesa (sin propiedad privada ni dinero) -que tampoco le parece entusiasmar-, como en indicarnos la senda seguida por un grupo de individuos en su aspiración por propiciar un escenario donde poder recuperar su posición central en el mundo y convertirse en los protagonistas y máximos ejecutores de sus decisiones. Una senda que para el autor es esencial, porque solo a partir de ella el ser humano podría ser verdaderamente libre para determinar el tipo de vida que desea para él y sus semejantes y, en consecuencia, optar por un mundo basado en la cooperación y la solidaridad u otro donde lo fuera por la rivalidad y el orgullo.

Para el autor de Utopía, una vez el hombre haya tomado conciencia de las razones de su padecimiento y se haya liberado de las falsas creencias que le han tenido alienado, volverá a ser libre y, por tanto, estará nuevamente en disposición de aspirar a cualquier tipo de escenario social. Del sentido de las nuevas normas y regulaciones que se apliquen dependerá el tipo de sociedad deseado, que Moro confía sea aquel que permita a los hombres orientar racionalmente sus intereses en la senda de la felicidad fraternal que, según él, Dios les ha inculcado.

El género distópico también ha discurrido en torno a similares planteamientos; si bien, bajo una perspectiva diametralmente opuesta a la seguida por Utopía: las pautas y reglas sociales descritas ya no persiguen extender valores y conductas positivas, sino más bien lo contrario: extraer lo peor de las personas. Ese es el caso de Battle Royale (Koushun Takami, 1999) o de Los juegos del hambre (Suzanne Collins, 2008-2010), dos novelas de muy similar corte donde se nos presenta a una serie de individuos recluidos forzosamente en un espacio aislado y debidamente delimitado (normalmente una isla) y obligados a adaptarse a una serie de reglas extremas de cuyo cumplimiento depende su supervivencia. En la medida en que dichas reglas imponen prácticas que transgreden su moralidad y valores, e intensifican su individualismo hasta el extremo podemos hablar de un escenario muy próximo al estado de naturaleza hobbesiano: lo que se persigue crear ya no es una sociedad integrada por seres humanos sino un agregado de agentes depredadores cuyo único y exclusivo fin es exterminar a los demás cómo única garantía de la supervivencia propia. 


\section{A MODO DE CONCLUSIÓN}

¿Existe algún nivel de paralelismo entre Utopía y lo que nos propone el género distópico? Sin afán de soslayar la infinidad de lecturas e interpretaciones a las que ha dado $-\mathrm{y}$ a bien seguro, seguirá dando- pie la obra ${ }^{22}$, nos permitimos, a la vista de todo lo anterior, avanzar algunas conclusiones provisionales:

a) A nuestro juicio, tanto la obra de Moro como la distopía moderna comparten una mirada esperanzadora en torno a la capacidad del ser humano para dar respuesta a las difíciles condiciones planteadas en el curso de su existencia y que en la mayor parte de los casos tienen su origen en la misma acción humana. Partiendo de que la sociedad y cuantas normas la conforman son artificiales, creadas por hombres al servicio de sus necesidades, nada -sostienen- debe impedir modificarlas o cambiarlas si ya no responden a las razones por las que fueron creadas. En este sentido, corresponde al hombre y sólo a él determinar tanto sus prioridades como el mapa de relaciones verdaderamente deseado.

b) En ambas tradiciones se recurre a toda una serie de técnicas y recursos literarios propios de la ficción -imágenes, paralelismos, símbolos, también visibles en los mitos-que invitan al ser humano a familiarizarse y reflexionar sobre el sentido de sus creencias y el valor real jugado por éstas en su vida. En este sentido, y en la línea de lo planteado por Fredric Jameson con respecto a los textos utópicos, el valor de estas propuestas no se explica tanto por lo que son sino por lo que hacen, al funcionar como crítica o como un tipo de provocación imaginativa, que anima a la contemplación tanto de lo que es como de lo que podría $\operatorname{ser}^{23}$

c) Tanto un género como el otro se sirven de la fabulación de la realidad para, mediante la crítica, sacudirnos de esa condición alienada que nos somete y nos aparta tanto de nosotros mismos como de nuestros semejantes. Siempre, por supuesto, contando con la complicidad del lector, a fin de cuentas el verdadero protagonista del relato, otro ser humano que como el resto de sus semejantes, se encuentra enfrentado a un mundo tan complejo e incontrolable que jamás podrá ser completamente suyo.

\footnotetext{
22 Para una visión general y amplia de las diferencias interpretaciones de la obra, George M. Logan and Robert M. Adams (eds.), More, Utopia (Nueva York: Cambridge University Press, 2002), y Anthony Pagden, The Languages of Political Theory in Early Modern Europe (Nueva York: Cambridge University Press, 1990), 123-157.

${ }^{23}$ Fredric Jameson, The Ideologies of Theory: Essays 1971-1986. Volume 2: The Syntax of History (Londres: Routledge, 1988), 76-77.
} 


\section{BIBLIOGRAFÍA}

Bellamy, Edward (2011), El año 2000 (Madrid: Capitán Swing,).

Bouchard, Guy, (1985); L’Utopie Aujourd'Hui (Quebec: Gaetan Morin.

)

Casey, James (2001), "Historiografía inglesa: tendencias recientes en el estudio de la época moderna", Chronica Nova 28, 105-127.

Claeys, Gregory (2016); Dystopia: A Natural History (Oxford: Oxford University Press), https://doi.org/10.1093/acprof:oso/9780198785682.001.0001.

Davis, James Collin (2000), “L'Utopie et le Nouveau Monde 1500-1700”, en Utopia. La quête de la société idéale en Occident, dirs. Lyman Tower Sargent y Roland Schaer (París: Bibliothéque Nationale de France - Fayard).

Gilbert, Daniel, (2006), Tropezando con la felicidad (Barcelona: Destino).

James, William (2004), La voluntad de creer (Madrid: Encuentro).

Jameson, Fredric (1988), The Ideologies of Theory: Essays 1971-1986. Volume 2: The Syntax of History (Londres: Routledge).

Logan, George M. and Adams, Robert M. (eds.) (2002), More, Utopia (Nueva York: Cambridge University Press).

Moylan, Tom (2000); Scraps of the Untainted Sky: Science Fiction, Utopia, Dystopia (Boulder: Westview).

Moro, Tomás (2005), Utopía (Madrid: Espasa Calpe).

Pagden, Anthony (1990), The Languages of Political Theory in Early Modern Europe (Nueva York: Cambridge University Press).

Sargent, Lyman Tower (1994); "The Three Faces of Utopianism Revisited," Utopian Studies 5-1.

Schulz, Kathryn (2015); En defensa del error (Madrid: Siruela).

Silver, Nate (2014), La señal y el ruido (Barcelona: Península).

Skinner, Quentin (1985), Los Fundamentos del pensamiento político moderno (México: Fondo de Cultura Económica). 
Suvin, Darko (2016), Metamorphoses of Science Fiction: On the Poetics and History of a Literary Genre (Berna: Peter Lang).

Thoreau, Henry David (1994), Walden (Nueva York: Peter Pauper Press).

Youings, Joyce (1984), Sixteenth-Century England (Londres: Penguin).

Recibido: 28 de marzo de 2017

Aprobado: 5 de octubre de 2017 